with occasional small imperfect giant-cell formations, and in the more densely infiltrated parts fungal grains could be seen irregularly distributed (see figure). Little in the way of detailed structure could be made out in the grains, and any attempt to culture them was obviously out of the question, but their appearance and relation to the associated histopathological changes are sufficiently typical to establish a diagnosis of mycetoma.

Acknowledgment.-We are indebted to the Director of the Sudan Medical Service for permission to publish this case.

\title{
REFERENCES
}

Christopherson, J. B. and Archibald, R. G. (1919).-Proc. Roy. Soc. Med., Vol. XII (Section of Ophthalmology), pp. 4-14.

Elliot, R. H. (1920).- Tropical Ophthalmology. London: Henry Frowde and Hodder and Stoughton.

Wilson, R. P. (1938).-12th Rep. Giza Memorial Ophthalmic Laboratory, p. 70. Cairo: Ministry of Public Health.

\section{THE DEVELOPMENT OF OPHTHALMOLOGY IN BOMBAY}

BY

LT.-Col. Sir J. N. Duggan, KT., C.I.E., O.B.E.,

D.O.(Oxon.), F.C.P.S., L.M. \& S.

PROFESSOR OF OPHTHALMOLOGY, GRANT MEDICAL COLLEGE, AND OPHTHALMIC SURGEON, SIR C. J. OPHTHALMIC HOSPITAL, BOMBAY

and

V. K. Chitnis, D.O.(Oxon. \& Bom.), M.B., B.S., F.C.P.S. HON. ASSISTANT SURGEON, SIR C. J. OPHTHALMIC HOSPITAL, BOMBAY

\section{Introductory}

THE origin and development of ophthalmology in the Bombay Presidency are closely bound with the establishment and growth of its medical institutions. No record, proving that ophthalmology was practised on scientific lines was available before these institutions came into existence. Even after the establishment of the Grant Medical College and the J. J. Hospital, it took some time for the teachers to evolve the different courses of instruction imparted in the institutions. Ophthalmology was considered as a minor branch of surgery and hence the course was limited to a couple of lectures delivered to the first batch of students of the College. It must, however, be said that the importance of this 
special branch of medicine was never lost sight of even in the early part of medical education in this Presidency and with the steady growth of the College and the Hospital, ophthalmology found its place in the curriculum and became a separate science. Special facilities for the teaching and treatment of eye diseases were provided for, culminating in the end into a special hospital for the same purpose. It is, therefore, necessary to turn our attention to the origin and growth of these institutions in order to see how ophthalmology attained its present status.

\section{Early History of Bombay Hospitals}

"The first hospital in India appears to have been that at Goa, mentioned in 'Fryer's Travels.' First hospital in Madras was opened in about 1664; establishment of a hospital in Bombay was under discussion in 1670 ; but apparently it was not actually opened till 1676; the earliest hospital in Calcutta dates from $1707-08$.

(1) The first suggestion of a hospital in Bombay seems to have been made in 1670 .

In the Surat Diaries, 1669- 75 , is given a Commission of Instructions, dated Bombay, March 5, 1669-70 showing that it had been determined to build a hospital in the town.

'It was found that the natural disease of the country was infectious and endangering the life of the garrison and so the need of building a hospital arose, but it was decided to build it as frugally as possible and only those to be admitted who would bear their own expenses for the benefit they would derive from the hospital.'

Apparently the project of opening a hospital hung fire for several years. Two plans of the proposed hospitals were sent for approval to the President and Council at Surat on November 23, 1675. The plans were received, acknowledged and considered. Eventually on July 19, 1676, they were approved ' We like well of your proposition of making the present court of judicature an Hospital.' Six months later, a letter from Bombay to Surat, dated January 24, 1676-77, reports that the new hospital has been opened and has proved of much service.

During the siege of Bombay by the Siddhi in 1689-90, a hospital ship was in use. An entry dated March 15, 1688-89, in the Bombay Diaries, Vol. III, 1684-90, states :-

' Dr. Michill came ashore from the hospital ship with a list of killed and wounded.'

The use of hospital ship for the reception and treatment of the wounded in war is usually considered an important advance in the military medicine of our time.

A quarter of a century later another modern development, 
female nursing in hospitals, seems to have been anticipated in Bombay. A Mrs. Pack had been sent out from England as matron for the Bombay Hospital, and had married soon after her arrival. She does not seem to have vacated her post on marriage. Her husband, Nicholas Hatch, was the Company's Master Carpenter.

A new hospital building was erected in 1733 near the marine yard, above the site of the modern Great Western Hotel.

As an outcome of disputes between two surgeons, John Neilson and Henry Compton, a standing committee was appointed. It consisted of the Marine and Land Paymasters and the Captain Commandant, to inspect the hospital monthly and report on it to the Council.

The Cons. of June 30,1738 , contain a report by the committee, and regulations for the hospital, also the existing staff and a proposed rearrangement thereof. Patients admitted were divided between the two surgeons, those admitred one week going to the first surgeon, those of the next week to the second surgeon. 'The pay of hospital assistants was fixed at six rupees, of outdoor assistants at eight rupees per month.

Another report by the standing committee of March 14, 1745-46, provided new regulations for the hospital, the chief of which were that the surgeons should visit the hospital twice daily at 8 a.m. and 4 p.m., that patients were to be divided equally between $\mathrm{Mr}$. Neilson and Mr. Mathison; that each had to keep charge of his own cases throughout, and that they had to consult each other in serious cases.

' Grose's Voyage to the East Indies' contains a plan of Bombay, in which the hospital and doctor's house (No. 7 in the plan) are shown as a large building near the shore, on the west of the harbour.

The Cons. of October 15, 1755, contain a report by the Hospital Committee, on which orders were passed that 'A room for chirurgical operations' should be built.

Bombay letter of February 4, 1771, reports in para. 37 that another set of new regulations for the hospital was drawn up and in para. 38, the erection of a ' chemical laboratory' was ordered.

The Cons. of December 24, 1773, gives the following subordinate staff in the hospital under the surgeons : Messrs. March, Crozier, Fleeming and King, each Rs. 76 per month; Mr. Didrot, Rs. 40; Messrs. Jenkins, Mathews and Cabral, each Rs. 30.

Of these, the Hospital Committee found Messrs. King, Jenkins and Didrot an encumbrance because they could not be relied upon for compounding and dispensing of medicines and hence they were recommended to be removed.

Francis Crozier entered the Bombay service as Assistant Surgeon in August, 1773 and became Head Surgeon on February 10, 1784, and member of the Medical Board on September 15, 1789, only 
sixteen years after the first appointment, an instance of very rapid promotion.

(2) In 1789 an old hospital, formerly used as a Hospital for men of the Royal Navy, was rebuilt on Old Woman's Island. A Bombay General Letter, dated February 21, 1769, reports in para. 19 :- Present hospital is too small, have appropriated one on Old Woman's Island used for the King's Service last war, and on February 11, 1768 we determined to fit it up in a commodious manner, but other buildings then carrying on, prevented our finishing it then, therefore on 7 th instant determined to complete it agreeable to the estimate delivered in amounting to Rs. 9,234.'

(3) The Bombay Cons. of February 28, 1769, order estimates for building a shed to be used as a hospital for sepoys. This hospital had only a short life of some fifteen years. A General Letter from Bombay, dated December 31, 1783, states in paras. 25 and 26:- The principal surgeon of the hospital having complained of an infringement of their contract by the Select Committee having abolished the Sepoy Hospitals, we issued orders countermanding that abolition, agreeably to the Surgeon's request.'

The Sepoy Hospital was, however, abolished by a G. O. of 1784. A Bombay General Letter of January 5, 1785, reports in paras. 27 and $30:-$ ' The Sepoy Hospital in its late form abolished and the President's plan for establishing Battalion Hospitals adopted. The future mode of conducting the European Hospital will soon be considered.'

The Cons. of September 26, 1781, mentions that the plans of the new hospital, prepared by the Principal Engineer are to cost Rs. $5,15,025$, and that the scheme must be postponed as too expensive.

Forbes, in ' Oriental Memoirs,' Vol. I, p. 152, states that when he left Bombay in 1784, there existed then three large hospitals ; one within the Gates for Europeans, another on the Esplanade for the Sepoys and the third for convalescents on the adjacent island (Old Woman's Island). The first of these three was the General Hospital of the day, the second and the third were opened in 1769 .

A letter from the Bombay Medical Board to the Council dated August 24, 1787 complains that only two surgeons are allowed to attend the sick of these three hospitals, which are all at some distance from each other, two of them being outside the gates; that two men cannot cope with the work, in addition to all their other duties; and that hitherto four have been allowed! They further state that the number of sick in the garrison much exceeds that at Fort St. George and is almost, if not quite equal to that at Calcutta; and that on the morning of the day they write there were 325 in-patients of whom 221 were Europeans in the three hospitals. 
A Bombay Military Letter of March 25, 1801 reports in para. 60 that the hospital within the Fort has been completed.

In 1824, new buildings were erected for the hospital on the Hornby Road. It took in the sick both of the garrison and the civil population. In 1861 the institution was moved to temporary quarters in the grounds of the Artillery Barracks in Fort George, and in 1876 to a building called the Officers' Quarters. The foundation stone of the present St. George's Hospital was laid on February 22,1889 , on the site of the old Fort George and the buildings were completed in 1892, at the estimated cost of Rs. 5,69,667, which was little higher than that of 1781 .

Some sort of native hospital was in use in 1809 and treated about twenty patients daily. It was supported by Government. The Bombay Native Dispensary was opened in 1834 and the Girgaum Dispensary in 1846.",

Just as the St. George's Hospital owes its origin to the first hospital built in 1670 , so also the present $]$. I. Hospital owes its origin to the Native Hospital in existence somewhere about 1809 .

The First Ophthalmic Institute.-It is not known whether any provision for the treatment of eye diseases was made in all these three hospitals, from their inception in 1670 and 1769. The first provision for the treatment of eye diseases is contained in a Bombay General Order of March 10, 1823, sanctioning the establishment of an ophthalmic institution in the city, and appointing Assistant Surgeon Richmond of His Majesty's 4th Dragoons, as Superintendent. This institution was absorbed in the J. J. Hospital in 1845.

Grant Medical College.-It was in the year 1826 that the first medical school was established in Bombay. This was the second school in the whole of the country. The first was established in Calcutta in 1822 and the third in Madras in 1827. The school in Bombay functioned for six years only and was abolished in 1832 . The second attempt made to establish an institution for imparting a higher type of medical education, proved successful, owing entirely to the genius and wise statesmanship of Sir Robert Grant, who became the Governor of Bombay in 1835. Soon after assumption of office, he devoted his attention to establishing a native medical school in the Presidency. The failure of the first school, however, made him cautious. As a first step in this direction, he founded the Medical and Physical Society of Bombay, to which the medical officers of the public services belonged. This Society is flourishing to-day as the Grant College Medical Society and probably it is the oldest medical society in India.

After this society was well organised, Government asked its Managing Committee to submit its matured opinion on the expediency of instituting a more complete and comprehensive system of medical education. At the same time, Government 
asked the opinion of the various medical officers of experience and other functionaries in several districts in the Presidency, regarding the conditions of medical practice that prevailed, and whether there existed any obstacles to the introduction of a better system.

After great deliberations regarding difficulties and prejudices that might crop up against the proposed institution, when he received a favourable report from the Committee of the Medical Society, Sir Robert Grant drew up a most able minute, in which the subject of the medical education of the natives of this Presidency was fully discussed and plans of instruction proposed, which form the groundwork of the system to be followed in the school which has been honoured with the name of this distinguished statesman. This was transmitted to Calcutta about the middle of the year 1838. It was approved by Lord Auckland's Government, but before this intelligence had reached Bombay, Sir Robert Grant died (July 9, 1838). The Hon'ble Court of Directors sanctioned the plan of a medical school as proposed by Sir Robert Grant, and authorized its being designated "The Grant Medical College."

The fund subscribed amounted to Rs. 44,800. The Hon'ble Court of Directors contributed an equal amount to defray the cost of the college building (total Rs. 89,906-4-2). The foundation stone of the college was laid on March 30,1843 by the Lord Bishop of Calcutta. It was completed in October, 1845 and was made over to the first Principal of the College, Dr. Charles Morehead.

J. J. Hospital.-Early in 1838, Sir Jamsetjee Jeejeebhoy offered to pay into the Government Treasury the sum of rupees one lakh, provided the Government contributed an equal amount. The income from this was to be spent on a hospital established for the relief of the "poor sick" of all denominations. It was finally decided to build the Hospital in the close proximity of the Medical College, to designate it the Sir Jamsetjee Jeejeebhoy Hospital, to construct it for the accommodation of 300 sick, just regard being paid to prejudices of caste, to close the Native General Hospital on the opening of the new institution, to constitute the Professors of the Medical College the medical officers of the Hospital and to place it under the control of the Superintending Surgeon and the Medical Board, subject to the scrutiny of an Honorary Board of three Managers of whom Sir Jamsetjee Jeejeebhoy or his representative was to be one, the other two being nominated by Government.

The foundation stone of the Hospital building was laid on January 3, 1843 with Masonic honours by the R.W. the Provincial Grand Master of Western India, Dr. James Burns, K.H.

It was opened for the reception of "the sick" in the month of May, 1845, when the Native General Hospital was closed, and its inmates transferred to the new building. 
The Grant Medical College and the Sir J. J. Hospital started on their career simultaneously in the year 1845 . October 20,1845 , was fixed for the examination of candidates for admission into the College, and on November 1, 1845, instructions began with 12 students on the rolls.

The subjects of study in the first year were anatomy and chemistry, the former being taught by Dr. John Peet and the latter by Dr. H. Giraud. In the second year the subjects of materia medica and institutes of medicine were further added and were taught by Dr. Charles Morehead.

The beginning of Ophthalmology.-The subject of anatomy was taught by the Professor of Anatomy and Surgery, Dr. Peet. The syllabus of anatomy included five lectures on the organs of special senses of which two were devoted to the study of anatomy of eye and its appendages, which was a well-nigh comprehensive and detailed study of the organ of vision.

In the second Annual Report (1846-47) of the Grant Medical College the following reference is obtained under the heading "Anatomical Museum ":-

"Thirty-two admirably executed diagrams of the anatomy and diseases of the eye have with the sanction of the Medical Board been transferred from the oculist's department to the museum of the College, and these will prove very useful indeed to the students at a more advanced period of their studies."

This reference lends support to the assumption that there existed an oculist who was interested in diseases of the eye and was engaged in preparing material to be made available at a future date for instruction in diseases of the eye. Who the oculist was is not clear from the Report. Probably he belonged to the Ophthalmic Institution first started in.1823.

Lectures and clinical instructions in surgery began in the third year (1847-48). The Professor of Surgery gave lectures on diseases and injuries of the eye and lacrymal apparatus. In the year 1849-50, 29 cases of ophthalmia were treated in the J. J. Hospital and three operations were performed for entropion.

In the same year under report, 107 cases suffering from acute diseases of the eye and 29 chronic cases attended the dispensary of the J. J. Hospital. All communities were represented in these diseases. Three cases happened to be of syphilitic iritis.

The doubt as to who the oculist was is cleared up by reading the Annual Report of the Grant Medical College for the fifth year (1850-51) in which it is laid down that " the fifth year students have all, in rotation of periods of three months, attended the eye dispensary, and have derived much advantage from the experience and able instruction of the oculist, $\mathrm{Mr}_{\mathrm{r}}$. R. D. Peele. This latter gentleman had voluntarily offered his services to teach midwifery at the commencement of the fourth year of the College along with 
Dr. W. C. Coles, M.D., who similarly volunteered to teach medical jurisprudence. It is evident from the fifth Session Report that $\mathrm{Mr}$. Peele was continuing as the oculist and looking after the eye dispensary or department in the J. J. Hospital while the lectures in ophthalmology were delivered by the Professor of Surgery.

In the year 1850-51, the first case of cataract was operated upon in the J. J. Hospital and discharged.

The final examination for the diploma of graduate was held in the year 1851, by the Government Examiner, wherein ophthalmology was included in the subject of surgery. Although no question or questions were set in the written examination, candidates were examined orally and questions were asked on varieties of ophthalmia, iritis, cataract and short sight. The operations asked for cataract, were extraction and depression. It appears from this that couching for cataract still created interest and was probably considered to be a rational mode of treatment of this condition, although it was replaced by extraction nearly a century before by surgeons on the Continent (Daviel, 1745). Couching is essentially an Indian operation, its pioneer being Sushruta of the Ayurvedic fame, and it is no wonder that this operation still created interest and held a place in the surgery of cataract in those days.

The Ophthalmic Dispensary.-The Annual Report of 1850-51 states that a building for the accommodation of the eye dispensary and the department of vaccination has just been completed in the compound of the college, so that the students would enjoy ample opportunity of making themselves acquainted with the diseases of the eye, and the course of the vaccine disease. The plan of the eye dispensary is given in the annual report of the Grant Medical College of 1852-53.

This dispensary was built over the same situation where the present hospital stands to-day. This building consisted of a small block of nine rooms, of which the first three contained the eye dispensary. The next three were occupied by the vaccination office and the last three were used as dispensary for women and children. The eye dispensary was without any beds, its patients being admitted into the J. J. Hospital for treatment. This tiny little structure may therefore be regarded as the first visible sign of scientific ophthalmology in the J. J. Hospital Compound. The present magnificent structure can be rightly said to have developed from this small nucleus.

The year 1851 was an epoch-making year in the history of medical education of this Presidency. It was in this year that the final examination for the Diploma was held after the establishment of the college in the year 1845 and the first batch of medica! graduates left the institution. 
The "Final Examination" was conducted by Dr. M'Lennan, Government Examiner, Mr. Stovell, Mr. Watkins, and Dr. Campbell, Government Assessors, and the following candidates were found qualified for the diploma of Graduate:-Sabastian Carvalho, Anunta Chandroba, J. C. Lisboa, Bhawoo Dajee, Atmaram Pandurang, Paul C. Gomes, Merwanji Sorabji, Burjorjee Dorabjee.

On the day of the presentation of diplomas to the graduates on Tuesday, April 15, 1851, on which many higher Government officials and distinguished visitors were present, Dr. Charles Morehead, the principal, opening the proceedings, referred to this day in the following terms:-

"This day is a great epoch in the history of the Grant Medical College. It commemorates the fulfilment of the statesman-like views which led to its origin, and silences we may hope for ever, the desponding forebodings which have more or less attended its progress. It is this day on which the first fruits of the college are to be presented to the people of Western India, in the eight young graduates who are now to receive from your hands the justlyearned title of ability to practise the arts of medicine and surgery."

Addressing the graduates he said:-

"You are the first approved and accredited agents in a great work of national amelioration; you are to go forth armed with great powers of conferring inestimable benefit on others, not only mitigating their physical suffering and soothing their mental anxieties but also in enlightening and elevating their minds. Should you fail in this great mission, should the expectation of the great and good man whose generous advocacy of the interests of the people of this country has thrown open to you the portals of science and been the means of placing you in the proud position which you are about to fill-should these expectations be doomed to disappointment, where will the blame lay? I must not conceal from you that it will be with yourselves."

Speaking about the graduates themselves, the Government Examiner-the Physician General, in his letter to the Secretary to Government, General Department, dated April 18, 1850, wrote as follows :-

" Having at one time my thoughts much directed towards the medical education of natives, I had never entertained a doubt that they were as capable of acquiring the preliminary information necessary for the foundation of the medical education as any man whatsoever; but I had entertained doubts as to their reasoning powers; and as to their correct and useful application of that preliminary knowledge to the recognition, discrimination and treatment of various forms and shades of disease not differing in name, though differing in other matters of far greater import than name. 
"The result of these examinations has gone far to removing my doubts on this subject; and as far as examination can test fitness for engagement in medical and surgical practice, the graduates of the Grant Medical College have proved their fitness to as great a degree as I believe is ever done in Europe."

The genius of Sir Robert Grant had thus triumphed. These eight young graduates were not only born out of the genius of Sir Robert Grant but they were the product of the indefatigable industry of Dr. Charles Morehead and his colleagues, who had tended and fostered this institution in its young days.

The effect of this was far reaching upon the public of this Presidency. These graduates were the pioneers-the torch-bearers, who kindled the flame of medical science in Western India which to this day has been kept alive by the hundreds who have flocked to this institution in the years following. With the steady growth of science, separate institutes for every branch of medicine slowly came into existence. Ophthalmology slowly began to assert itself and it no longer remained a neglected branch of medicine.

The question of increasing the number of Professorships in the College was brought to the forefront in the year 1854-55, with a view to bringing the College under the regulations of the examining bodies of Great Britain. Sanction was obtained from the Honorable the Court of Directors and Chairs of anatomy and surgery and that of chemistry and materia medica were separated and a new Chair of ophrhalmology was established. The first gentleman to adorn this Chair (of ophthalmology) was Mr. H. J. Carter, M.R.C.S. who was appointed the acting Professor of Ophthalmology, Mr. Peele having resigned. This separation led to increase in the number of lectures in these subjects and to a more extended course of instruction in botany, practical toxicology and ophthalmic surgery.

A comprehensive course of lectures on eye diseases was drawn up and in the same year Mr. Carter submitted his report as follows :-

" The course of ophthalmic surgery consisted of 26 lectures (as against three only in the former years delivered by the Professor of Surgery and included in his subject), 20 examinations, during which the anatomy of the eye and its appendages was minutely described, and its physiology, so far as this relates to the understanding and treatment of ophthalmic affections.

" Inflammation specially, and then generally, as regards the entire organ, was fully considered, and its treatment. The inflammatory affections of the superficial structures, and of the deep seated or internal structure, were severally described and accompanied by their treatment respectively. The morbid affections of the lids, and the malignant disease of the eye, were described, 
with their treatment, and successively those of the retina and optic media. Lastly, the diseases of the lacrymal apparatus, and their treatment, was described.

"All the operations which are chiefly performed for remodifying morbid alterations in the lids, and external parts of the eye, as well as those which are performed on iris and lens, for the restoration of sight, were detailed, and the course generally illustrated by diagrams, so far as the resources of the College should permit."

Whereas the whole subject of ophthalmology was briefly considered in three lectures in the course of surgery, the subject as dealt with now in greater detail and as many as 26 lectures were required to cover the whole subject-a fact which easily proves the comprehensive manner in which ophthalmology was taught from this year onwards.

A wider interest in the subject of ophthalmology was being taken by the Graduates of the College. A Medical Society was in existence under the name of Grant College Medical Society. This society was really the continuation of the Medical and Physical Society originally started by Sir Robert Grant. The body met often and its deliberations were presided over by the Professors of the College, who ably guided its proceedings. Papers were read on widely different subjects and discussed by the graduates and professors of the College with a view to stimulate research and better understanding of the more difficult problems involved in the practice of medicine and surgery. Even ophthalmic problems received attention of its members, as can be seen from the proceedings of this society in the year 1854-55, when Mr. Lisboa described a successful operation for cataract in which the lens was absent, and the opaque capsule was attached to the iris by a pedicle.

In the year 1854-55, an important step in the advancement of native medical education was effected, in the recognition of the college by the Roval College of Surgeons of England as one of its affiliated schools for medical instruction. In the year 1855-56, a similar recognition was granted by the University of London. With a view to taking advantage of this recognition, one of the graduates, Mr. Rustomjee Byramjee, proceeded to England in June, 1855 to obtain higher qualification.

It is very significant to remark that this same graduate received the diploma of the Royal College of Surgeons of London, obtained the degree of Doctorate of Medicine from the University of St. Andrews and successfully competed for the appointment of Assistant Surgeon in the Indian Service in the year 1856-57. He had thus the honour of being the first Indian to have crossed the seas to obtain a higher qualification in England, and he did so very creditably indeed. 
The Bombay University was established in the year 185\%. In the year 1860-61 a new change came upon the College. The examination for admission into the College was abolished and the Matriculation Examination of the University was substituted for it. Moreover, the power of granting diplomas which was possessed by the college, was ultimately withdrawn and the examination for licence of practice, or for a degree, was held by the University. The College was thus affiliated to the University.

From here onwards we have no records available to show the progress of ophthalmology. But a very significant change took place within a couple of years. It is not necessary to dwell here upon the deep impression the college and its allied institutions had made upon the public. Scientific medicine had firmly estab. lished its reputation in Western India and had once and for all set at rest the fears of the orthodox mind. The usefulness of these institutions had been proved beyond doubt. No pains were spared to maintain the standard of instructions at a higher level. Many public-spirited gentlemen had offered prizes and scholarships by way of encouragement to the students. Even the long-felt want of a lying-in hospital was supplied by the munificent donation of Sir Jamshedjee Jeejeebhoy, to which large sums were contributed by many generuus individuals. This obstetric institution came into existence in 1853 . The modest little dispensary for the treatment of eye diseases was doing its useful work. But it had no beds. Its patients had to be admitted to the J. J. Hospital for treatment. It needed a building of its own and without one its services could not be established on a more organised basis. It had proved its usefulness beyond doubt. The public were deriving great benefit from the efficient treatment administered to the patients attending it. It was therefore sorely in need of a building of its own wherein it could treat both the out-patients and inpatients as well. The silent appeal that this ophthalmic dispensary made to the general public did not fail to evoke sympathy in the hearts of its generous admirers. Early in the year 1863 a philanthropic donor came to its rescue.

\section{The Sir C. J. Ophthalmic Hospital, Bombay}

In the year 1863, the first Baronet, the then Mr. Cowasji Jehangir, made a munificent offer of Rs. 50,000 to the Governor in Council, towards the construction of an eye hospital on the premises of the Grant Medical College. Government accepted the offer with thanks and the India Office in their letter of June 25, 1863, wrote in reply to His Excellency the Governor in Council, Bombay, as under:-

"I do not doubt that the construction of a building especially adapted for the treatment of diseases of the eye 
will be found highly beneficial and I have to request that Mr. Cowasji Jehangir may be informed of the high sense I entertain of his liberality in contributing so largely towards the provision of such a building."

The total cost of erecting the building, however, came to Rs. 97,143, and although Sir Cowasji's offer was of Rs. 50,000, he was so generous that he defrayed the total cost of constructing the hospital which bears his name. After the completion of the building the Governor General in Council sent their acknowledgment to the " philanthropic donor," and Sir Charles Wood, the then Secretary of State, wrote from London to express the sincere thanks of Her Majesty's Government to Mr. Cowasji Jehangir. Thereafter the Government of Bombay congratulated Mr. Cowasji Jehangir by passing a resolution in Council as follows :-

"His Excellency the Governor in Council congratulates $\mathrm{Mr}$. Cowasji Jehangir on the completion of this building, which will prove a lasting memorial of his philanthropy."

The Sir Cowasji Jehangir Ophthalmic Hospital thus came into existence for the first time on July 21, 1866, twenty-one years after the inauguration of the Grant Medical College, and the Sir Jamshedji Jeejeebhoy Hospital. It is situated at the South-West corner of the J. J. Hospital Compound and forms one of the group of hospitals situated in this compound affiliated to the Grant Medical College for teaching purpuses.

The hospital then provided an out-patient department and indoor accommodation of 40 beds. It contained six large rooms and several small rooms; of the large ones, three were used as male wards of 28 beds and one as a female ward of 12 beds. The fifth and sixth rooms were used as waiting and prescribing rooms. This was the first organized attempt to treat diseases of the eye separately, the need for which was long felt, even in those days, and as years rolled on, the necessity and utility for such an institution began to increase and the need for its further extension arose; as the hospital was found to be too small for the needs of a large city like Bombay and admission was almost entirely restricted to patients requiring the more important and delicate operations, chiefly cataract extraction and glaucoma operations, while cases with ulcers and such other diseases had to be refused admission. The hospital served also for practical instruction to the students of the Grant Medical College, and as long as their number was limited, this was carried on satisfactorily, but year after year the number of students kept on increasing, this being the only medical college in the whole of the Presidency. Consequently teaching had greatly suffered through want of accommodation and adequate facilities for this purpose. Also, as the demand for beds in the hospital was increasingly felt, matters were again represented by Col. H. Herbert, I.M.S., the then ophthalmic 
surgeon, to Sir Jehangir Cowasji Jehangir, the Second Baronet, in the year 1906, i.e., forty years later, and the Baronet readily offered to place at the disposal of the Government a sum of Rs. 25,000 towards the cost of constructing a new building on the following conditions:-

"That the old and new buildings be named "The Sir Cowasji Jehangir Ophthalmic Hospital.'

That a medallion bust of the late Sir Cowasji Jehangir be placed in a conspicuous place to be selected in consultation with the donor, accompanied by a tablet reciting the name of the hospital.

That a special ward to contain at least eight beds be reserved for Parsi patients, a tablet being affixed at the entrance of the ward inscribed 'The Sir Cowasji Jehangir Ward for Parsis only."

As the building was estimated to cost Rs. 58,290, Sir Jehangir generously increased his contribution to Rs. 30,000 , to enable the Government to commence work without delay.

His Excellency the Governor in Council was pleased to accept with gratitude the offer made by Sir Jehangir. The Governor in Council desired to take that opportunity of giving public expression to his appreciation of the liberality of Sir Jehangir Cowasji Jehangir, which enabled provision to be made for the much needed addition to the existing accommodation in the ophthalmic hospital.

Accordingly, His Excellency the Rt. Hon'ble Lord Lamington, G.C.M.C., G.C.I.E., Governor of Bombay, laid the foundation stone of the Sir Cowasji Jehangir Ophthalmic Hospital Extension on September 25, 1906. It was completed in December, 1908. The cost of this amounted to Rs. 71,175, of which the sum of Rs. 30,000 was contributed by Sir Cowasji Jehangir.

This extension provided an out-patient department, major operation room, 14 additional beds, a nurses' room, and the surgeon's room. The out-patient department included waiting room, general out-patients' room, minor operation room, dark room, dispensary, pathological room, and refraction room. The indoor accommodation was thus increased to 73 beds. In this way the new block allowed considerable expansion of out-patients' work, afforded ample facility for teaching purposes and provided a few more beds for the admission of patients other than those requiring operative treatment.

The life of the hospital was thus put on a firmer basis and the work continued onwards with unstinted zeal. Meanwhile the science of ophthalmology was growing and newer methods and scientific appliances for diagnosis and treatment of eye diseases were coming into vogue every day. The mental outlook of the 
public was changing as days passed by. Men were crowding the hospital in larger numbers, as they began to realize the value of accurate diagnosis and scientific methods of treatment available in this institution which could boast of being the one and only hospital of its kind in the whole of the Presidency, to say nothing of the smaller hospitals and dispensaries that sprung up later on. One fact alone suffices to prove the force of this argument. Whereas in the year 1872 the total number of cases treated and operations performed was 5,169 and 448 respectively, in the year 1927 it was 14,588 and 4,200. Above all, the appalling blindness in the country in general and the Presidency in particular was very keenly felt. For the treatment of preventable blindness it is necessary to provide for a separate septic ward. Owing to the limited accommodation of 73 beds it was not possible to admit these cases. The havoc played by ophthalmia of the new born and venereal ophthalmia, to say nothing of that highly contagious and infectious disease trachoma, which is blinding the population of this Presidency in larger numbers, in augmenting the number of the totally blind, has yet to be fully realized. But as long as provision was not available for such cases, nothing could be done. The need for extension of the indoor accommodation was all the more felt in view of the fact that post-graduate teaching had increased in the institution and up-to-date provision had to be made for maintaining the high standard of teaching. A large number of students of this institution used to go abroad for higher qualifications in ophthalmology. The success that these students achieved in England in obtaining D.O. and D.O.M.S. diplomas within a short space of a few months of their completion of postgraduate work at this institution, stimulated Sir Jamshedji Duggan to obtain further means to raise the standard of teaching by increasing the available resources for this purpose. Further, the University of Bombay was then considering the question of instituting the diploma in ophthalmology. Moreover, the indoor accommodation needed a radical change in its outlook. The old wards offered a clumsy contrast to the 1906 extension. They were ill ventilated, dark and dismal looking and were situated on the ground floor only. The necessity to rebuild them on the most modern and up-to-date principles of hygiene and sanitation was very keenly felt as our ideas about the treatment of eye diseases were rapidly changing with the advancement of science. With these considerations weighing in his mind, Sir Jamshedji appealed to Sir Cowasji Jehangir (Second Baronet) to rebuild the hospital with increased accommodation, the urgent necessity of which was being felt every day.

Sir Cowasji Jehangir was so greatly impressed that he readily responded to this appeal for the rebuilding of the hospital with which the name of his family has been so long and worthily 
associated. He generously offered to give a munificent donation of rupees one lakh and a half for utilizing it in the best way possible in furtherance of the proposal to rebuild the ophthalmic hospital. Sir Cowasji Jehangir (Second Baronet) thus came for the second time to the assistance of this institution founded by his late father.

Sir Leslie Wilson, the then Governor of Bombay, had inaugurated a fund for the extension and improvement of the existing hospitals and building up newer ones for the special needs of the people of this Presidency-called then "The Sir Leslie Wilson Hospital Fund." After Sir Cowasji Jehangir had made his princely offer of a lakh and fifty thousand rupees for rebuilding and increasing accomodation in the hospital, an equal amount was added from the above fund and the new building of four storeys was erected on the present site at a total cost of Rs. 3,03,983-15-4.

The foundation stone of this new building was laid by $\mathrm{His}$ Excellency Sir Leslie Wilson, the then Governor of Bombay, on November 20,1928, and after the completion of the new hospital building it was taken into use from October, 1930.

The hospital has now an accommodation of 100 beds. It has a separate ulcer ward for the treatment of infectious diseases, and a special operation theatre for septic and minor operations has also been added. The hospital is equipped with the best and most modern appliances for the diagnosis and treatment of eye diseases. The out-patient department is large and is able to meet the demands of about three to four hundred patients daily. The building is four storeyed and possesses a simple yet magnificent structure and occupies the most enviable corner of the J. J. Hospital compound.

The fame and status of this hospital are no longer local. This "Urbs prima in Indis," can justly be proud of possessing an ophthalmic hospital which has acquired an international reputation. Among the visitors attracted to this hospital from overseas were some of the most eminent ophthalmic surgeons, who were very much impressed with the high standard maintained in the treatment of cases as well as in the instruction imparted. To many of these distinguished visitors the high standard maintained in every department of this hospital came as a sort of revelation. This hospital can compare most favourably with any of the firstclass ophthalmic hospitals of the world, and there is no dearth of any clinical material.

To Sir Cowasji Jehangir Readymoney the public of Bombay owe a deep debt of gratitude for the munificent donations his family has freely contributed from time to time in bringing this hospital into existence and making it the most modern and up-to-date institution in the whole of the Presidency. It is the life work of a family that was mainly responsible for this princely charity 
and this hospital will stand as an everlasting memorial of their philanthropy. It is a child born out of charity and entirely devoted to charity.

The following are the names of the ophthalmic surgeons in charge of the Sir Cowasji Jehangir Ophthalmic Hospital, Bombay, since the year it came into existence, namely 1866 :-

1866 to July, 1867.--Surgeon-General Sir William Guyer Hunter, M.D., F.R.C.S.E.

July, 1867 to January, 1872.-Major J. H. Sylvester, M.R.C.S., F.G.C.

January 28, 1872 to May 31, 1895.-Brigade Surgeon Lt.-Col. George Archibald Maconachie, M.D., C.M.(Aber.).

June 1, 1895 to April 19, 1907.-Lt.-Col. H. Herbert, I.M.S.

April 20, 1907 to February 28, 1914.-Lt.-Col. P. P. Kilkelly, M.B., I.M.S.

March 1, 1914 to December 31, 1922.--Lt.-Col. G. McPherson, M.A., M.B., C.M., F.R.C.S.E., I.M.S., C.I.E.

January 1, 1922 onwards.-Lt.-Col. Sir J. N. Duggan, Kt., C.I.E., O.B.E., D.O. (Oxon), F.C.P.S., L.M. \& S.

\section{REFERENCES}

1. History of the Indian Medical Service, 1600-1913. By Lt.-Col. D. G. Crawford, Vol. II, pp. 391-400.

2. Grant Medical College Annul Reports, 1845-1862.

\section{MICROPHTHALMIA AND THE VISUAL PATHWAYS A Case Associated with Blindness and Imbecility, and Sex-linked}

BY

S. E. Whitnall and R. M. Norman

BURDEN MENTAL RESEARCH TRUST, STOKE PARK COLONY, BRISTOL

IN this investigation the chief points-beyond the history and observations of the patient during life-are the gross and microscopical features of the eyeballs; then of the visual pathways, traced along the optic nerves, chiasma and tracts to the lower visual centres in the midbrain; finally the brain as a whole, and the cortical visual areas in particular, were examined.

(The remarkable and possibly unique feature of this eye condition being a recessive sex-linked one has already been the subject of a paper by Dr. Fraser Roberts (1937), the genealogy showing 14 cases, all males, traced in four generations.) 